\title{
HIJOS DE LA VIOLENCIA: POLÍTICAS Y JUVENTUDES POST TRANSICIÓN DEMOCRÁTICA EN PERÚ
}

\author{
LUIS W. MONTOYA CANCHIS*
}

\begin{abstract}
RESUMEN
El trabajo examina las políticas aplicadas en relación a las juventudes de Perú después de producida la última transición democrática, a fines del año dos mil, luego de la caída del régimen del presidente Alberto Fujimori. Centra su atención en el análisis de las iniciativas emprendidas durante la gestión del presidente Alejandro Toledo y la actual gestión del presidente Alan García. Analiza el proceso seguido en la creación y posterior desactivación del Consejo Nacional de la Juventud, y evalúa su carácter de mecanismo de «inclusión participativa» de las juventudes, señalado durante la gestión del presidente Toledo. También señala la labor actual de la Secretaria Nacional de la Juventud, como parte de las labores del Ministerio de Educación, surgida del proceso de reforma del Estado implementado por el presidente García. Resalta los impactos que las políticas de liberalización de mercados vienen provocando en las juventudes peruanas después de producida la transición democrática.
\end{abstract}

PALABRAS CLAVE: POLÍTICAS PÚBLICAS, REFORMA DEL ESTADO, CONAJU, SECRETARÍA NACIONAL DE LA JUVENTUD

* Sociólogo, docente de la Universidad Nacional Mayor de San Marcos, Lima, Perú; y consultor en planificación del desarrollo de UNICEF Perú y Plan Internacional. E-Mail: lwmontoya@gmail.com. 


\title{
FILHOS DA VIOLÊNCIA: POLÍTICAS E JUVENTUDES PÓS-TRANSIÇÃO DEMOCRÁTICA NO PERU
}

\begin{abstract}
RESUMO
Este trabalho examina as políticas aplicadas às juventudes do Peru depois da última transição democrática, no final do ano 2000, após a queda do regime do presidente Alberto Fujimori. Enfoca a análise das iniciativas empreendidas durante a gestão do presidente Alejandro Toledo e a atual gestão do presidente Alan García. Analisa o processo que se seguiu à criação e posterior desativação do Conselho Nacional da Juventude, e avalia seu caráter de mecanismo de «inclusão participativa» das juventudes, destacado durante a gestão do presidente Toledo. Também aponta o trabalho atual da Secretaria Nacional da Juventude, como parte dos trabalhos do Ministério da Educação, surgida do processo de reforma do Estado implementado pelo presidente García. Ressalta os impactos que as políticas de liberalização de mercados vêm provocando nas juventudes peruanas depois da transição democrática.
\end{abstract}

PALAVRAS CHAVE: POLÍTICAS PÚBLICAS, REFORMA DO ESTADO,
CONAJU, SECRETARIA NACIONAL DA JUVENTUDE

\section{CHILDREN OF VIOLENCE: POLITICAL AND POST-YOUTH DEMOCRATIC TRANSITION IN PERU}

\begin{abstract}
This endeavour examines the policies applied in relation to Peruvian youth after the last democratic transition was produced, at the end of year 2000, after the fall of the regime of President Alberto Fujimori. This work focuses attention on the analysis of the initiatives undertaken during the management of President Alexander Toledo and the present management of President Alan García. It analyzes the process followed in the creation and later decontamination of the National Council of Youth, and evaluates its character of mechanism of «participating inclusion» of youth, indicated during the management of President Toledo. Furthermore, it indicates the present work of the National Secretary of Youth, as part of the workings of the Ministry of Education, arisen from the reformation process of the State implemented by President García. It emphasizes the impacts that the policies of liberalization of markets have caused in Peruvian youth after the democratic transition was produced.
\end{abstract}


KEY WORDS: PUBLIC POLICIES, REFORMATION PROCESS OF THE STATE, CONAJU, NATIONAL SECRETARY OF YOUTH

A la memoria de JAVIER ROCA CASAS

y KENNETH NEY ANSUALDO CASTRO, estudiantes de la Universidad del Callao, desaparecidos en 1993.

\section{INTRODUCCIÓN}

LA NARRATIVA PERUANA JOVEN más reciente, no ha perdido la característica de brindar lecturas indagatorias sobre la realidad social del Perú. La novedad es que ahora, a diferencia de décadas anteriores, existe una heterogeneidad de narrativas, como resalta García (2006). Los escenarios y personajes adquieren protagonismo en medio de desencuentros sociales y políticos, al mismo tiempo, los mundos interiores, la vida privada, la intimidad, son expuestos con especial énfasis y en medio de búsquedas de identidades diversas y complejas.

Una parte de esta heterogeneidad gira en torno a la violencia vivida en el Perú. No es posible ocultar que ella ha dejado su huella en las vidas de un sector mayoritario de la población. Planas (2007) con sutileza denomina como hijos de la violencia a sus narradores y señala a Santiago Roncagliolo y Daniel Alarcón como ejemplos.

Roncagliolo desde sus primeros relatos contenidos en Crecer es un oficio triste, presenta personajes diversos afectados por la violencia política. Abril Rojo narra las vicisitudes del fiscal Félix Chacaltana y su transformación en un perturbado combatiente de la guerra vivida en Los Andes peruanos. La cuarta espada, reconstruye la vida de Abimael Guzmán, líder de Sendero Luminoso.

Por su parte, Daniel Alarcón en Guerra a la luz de las velas, muestra las vivencias de migrantes andinos de Lima e hispanos en New York, donde el desarraigo es común; pero también la violencia. Radio ciudad perdida trata sobre la post guerra y los esfuerzos realizados por Norma, una locutora radial que convoca a las familias de los desaparecidos de un país sin nombre.

Sin embargo, quisiéramos permitirnos incluir en esta denominación a otro autor, Oscar Malca, que con la misma perspicacia aborda el tema de la violencia; pero lo hace con un matiz, desde la violencia vivida a nivel cotidiano, fruto de la frustración y el desarraigo. En su novela, Al final de la calle, donde con un lenguaje crudo - como señala Jorge Coaguila (2006) — muestra una Lima violenta, mísera y 
poblada por jóvenes desempleados que gastan sus días en las esquinas, envueltos en drogas, rock y sexo.

La denominación hijos de la violencia, no sólo es aplicable entonces a Roncagliolo y Alarcón, sino también a Malca, e incluso a toda una generación. No es arbitrario usarla al constatar las experiencias comunes de los jóvenes peruanos de hoy. Muchos nacidos años después viven las secuelas de la violencia y la sienten parte de su cotidianidad. La violencia callejera protagonizada hoy por pandillas, en varias ciudades del Perú que fueron antes azotadas por la guerra, es una muestra. La precariedad en la inserción laboral provocada por el desempleo y subempleo, la marginalización, la exclusión, la pobreza, son otras muestras. Las políticas de liberalización de mercados, aplicadas con gran dureza desde comienzos de la década del noventa del siglo XX, han ido de la mano con el aumento de la desigualdad y las condiciones de inseguridad y violencia.

Producida la última transición democrática, a fines del año dos mil, luego de la caída del régimen del presidente Alberto Fujimori, las iniciativas emprendidas durante la gestión del presidente Alejandro Toledo y la actual gestión del presidente Alan García, no han cubierto las brechas que afectan especialmente a las juventudes peruanas y tampoco han enfrentado la acelerada agudización de las condiciones de inseguridad y violencia que, en más de un caso, tienen como protagonistas a los y las jóvenes.

La paradoja no deja de sorprender: la recuperación de la democracia supone la afirmación de la ciudadanía, al menos desde una perspectiva democrático liberal, es decir, el ejercicio pleno de los derechos civiles, sociales y políticos. Las juventudes en el Perú con la recuperación de la democracia no gozan de un ejercicio pleno de su ciudadanía, por las brechas que las afectan. ¿Por qué las políticas implementadas desde el Estado post transición democrática en Perú no han enfrentado esta problemática?

\section{2. ¿POLÍ́TICA DE «INCLUSIÓN PARTICIPATIVA»? ${ }^{1}$}

El presidente Alejandro Toledo asume su mandato en medio de un contexto de grandes expectativas sociales. El liderazgo que ejerció en

1 Una aproximación a las políticas implementadas en relación a las juventudes peruanas durante la gestión del presidente Toledo fue realizada en un trabajo anterior, al respecto ver Montoya (2006). El presente trabajo recupera el avance antes realizado. 
la lucha contra el régimen autoritario y corrupto del presidente Alberto Fujimori, a través de un intenso proceso de movilización ciudadano y popular, provocó una gran identificación social y cultural en amplios sectores de la sociedad peruana.

Expectativas abiertas también en sectores sociales específicos, como las juventudes, que no sólo participaron con su voto en las elecciones donde fue elegido, sino que además, un importante sector de ellas, se movilizó en la lucha contra el autoritarismo y, en mayor o menor medida, expresaron el hartazgo con el sistema político y económico de carácter excluyente que imperaba.

Por ello, no sorprende que pasadas las elecciones y electo como presidente Alejandro Toledo, en su mensaje de asunción de mando, el 28 de julio de 2001, retome una de sus promesas electorales y anuncie la creación del Consejo Nacional de la Juventud (CONAJU), como parte de una alianza a largo plazo con los jóvenes del Perú. Esta medida que simbólicamente mostraba el reconocimiento público de Toledo del rol que las juventudes habían cumplido en la recuperación de la democracia y la necesidad de incluirlas, a través de su participación, ${ }^{2}$ a los procesos de desarrollo del país.

El anuncio presidencial es seguido de varias iniciativas legislativas, puestas en marcha desde el Congreso, que pretenden hacer realidad la propuesta de generar una institucionalidad pública en materia de juventudes desde el Estado.

Sin embargo, la improvisación del anuncio presidencial fue notorio porque el primer anteproyecto de norma de creación del CONAJU, planteado por el gobierno, fue prácticamente puesto a discusión pública después de dos meses de producido el anuncio presidencial. El gobierno publica recién el 29 de septiembre, en el Diario Oficial El Peruano, el anteproyecto de ley de creación del Consejo Nacional de la Juventud, tarea encargada al vicepresidente Raúl Diez Canseco, a

2 La noción participación genera muchos debates, por ella entendemos los esfuerzos de los «hasta aquí excluidos» por ampliar su control sobre los recursos, sobre los procesos de toma de las decisiones y sobre las instituciones de decisión y control de la sociedad. Otra acepción la define como mecanismo para incluir demandas en el Estado (la cual parece ser la perspectiva que manejó la administración del presidente Toledo). Nuestra perspectiva considera que es un proceso a través del cual se persigue la socialización del poder. Los varios abordajes a esta noción pueden ser apreciados en textos como el de Quijano (1991) o Kliksberg (1999). 
fin de animar un proceso de discusión pública a nivel nacional, que el propio presidente Toledo incentiva a llevar adelante.

El vicepresidente Raúl Diez Canseco, provenía de las filas de Acción Popular, un antiguo partido de centro derecha, tenía amplia experiencia política y era un empresario conocido por su labor en el campo de la responsabilidad social dirigida a jóvenes. Su intervención fue determinante, junto a las iniciativas parlamentarias, en la aprobación de este anteproyecto. ${ }^{3}$

La Ley del Consejo Nacional de la Juventud $N^{\circ} 27.802$ es promulgada un año después de su anuncio, el 29 de julio de 2002 por el presidente Toledo. El problema no sólo fue la demora en la promulgación de la norma, sino sobre todo el enfoque. La propuesta inicial del gobierno apostaba por un proceso de «inclusión participativa» de las juventudes, a través de la creación de una instancia de representación juvenil de base territorial elegida por voto universal, la cual es reemplazada por otra donde la participación de las juventudes es mediada y subordinada a una instancia estatal de rango ministerial.

La norma aprobada, señala que el CONAJU: «es un ente sistémico que se rige por los principios de identidad, transparencia, participación, concertación, coordinación, representación e institucionalidad democrática y descentralizada». El texto de la ley establece y regula la conformación de tres instancias: una de concertación, denominada el Comité de Coordinación del CONAJU, donde coordinan representantes de las juventudes y el Estado; un ente rector, la Comisión Nacional de la Juventud, que funciona como una organismo del Estado; y una tercera de representación juvenil, el Consejo de Participación de la Juventud, donde participan jóvenes de diversas organizaciones elegidos para este propósito.

La intención aparente, detrás de la ley, era abrir un canal de «inclusión participativa» a las juventudes; pero que no tuviera autonomía. Además, y al mismo tiempo, una instancia de diseño y gestión de políticas públicas en materia de juventud, que controlara recursos y deci-

3 Raúl Diez Canseco recibió en el 2000 el Premio Empresario Social otorgado por el Banco Interamericano de Desarrollo (BID). Diez Canseco es reconocido por implementar un fondo de crédito para proyectos de negocios presentados por jóvenes, proyecto financiado por el BID, la Corporación Andina de Fomento, el Banco Santander Central Hispano, el Banco Sudameris (donde Eliane Karp, esposa del presidente Toledo, era funcionaria y apoyó la iniciativa), entre otras instituciones. 
siones. Finalmente un ente de coordinación dentro del Estado en materia de juventud.

El cambio de enfoque, y los cuestionamientos que generó todo el proceso de creación del CONAJU, ${ }^{4}$ debió mucho a la improvisación y la necesidad de resolver de manera rápida compromisos adquiridos durante la campaña electoral, a fin de mitigar expectativas y cuestionamientos crecientes generados, desde los primeros meses de gobierno, por promesas electorales que, si bien eran difíciles de cumplir en poco tiempo, fueron la base de diversos cuestionamientos. Sumó a lo anterior el desconocimiento de las especificidades de la realidad juvenil y los modos más adecuados de definir cómo relacionarse con las juventudes desde el Estado.

Sin embargo, además de todo lo antes señalado, resultó también determinante la ausencia de una dirección política clara de lo que se quería hacer en el campo de las políticas dirigidas a las juventudes, y en las políticas sociales en general dirigidas a jóvenes, por parte del gobierno.

Situación que impidió establecer prioridades en la intervención, así como evitar la dispersión de sus acciones en varios frentes. No debemos olvidar que la propuesta de «inclusión participativa» de las juventudes, anunciada por el presidente Toledo, nunca llegó realmente a ser dilucidada. Nunca quedaron claro los alcances de la política que pretendía implementar. Lo que sí fue evidente es que la ley aprobada no le otorgaba a las juventudes del Perú la capacidad de incidir de manera efectiva, o tomar decisiones reales, sobre políticas públicas y en el conjunto de la acción del Estado.

Además la duplicidad, la desarticulación, el desorden, la dispersión y el limitado alcance de las intervenciones y en general de la oferta de servicios dirigida a jóvenes desde el Estado, registrada en los noventa durante la gestión del presidente Fujimori, no fue corregida durante la administración del presidente Toledo, sino simplemente

4 El Grupo de Trabajo Conjunto de ONG y Movimientos Juveniles (Contrajo) de la Conferencia Nacional sobre Desarrollo Social (CONADES), manifestó en más de una oportunidad sus observaciones a las iniciativas realizadas para crear el CONAJU. Otro colectivo de ONG, donde figuraban Redes Jóvenes, CEP, APJ, Instituto Alameda, Adeese, Democrática, con apoyo del Fondo de Población de Naciones Unidas y de Policy Project, manifestaron su «sincera preocupación» sobre el proceso puesto en marcha e intentaron incidir en el diseño de la propuesta normativa e institucional, sin mucho éxito. Otro colectivo que hizo sentir su voz vigilante fue Entrepares conformado por CEDEP, SPAJ, FOVIDA, entre otras instituciones. 
ubicada dentro de un marco institucional burocrático que no lograba generar cambios reales.

La Comisión Nacional de la Juventud (2004), durante la propia gestión del presidente Toledo, identifica 112 programas y proyectos orientados hacia una oferta universal dirigida a las juventudes desplegada de manera paralela y sin dirección definida. El informe precisa:

Diez sectores, además del Poder Judicial —a través de la Gerencia de Centros Juveniles - cuentan con información presupuestal 2004 relativa a proyectos y programas vinculados con población joven, contenida en sus correspondientes planes operativos [...] el presupuesto para programas y proyectos relacionados con jóvenes a cargo de diversas entidades públicas, alcanza alrededor del $5 \%$ del presupuesto total del sector público; ello sin considerar los esfuerzos que se realizan en los gobiernos locales y regionales (2004:23-24).

El problema no está restringido a las políticas dirigidas a las juventudes sino al conjunto de la política social. El desmantelamiento de las estructuras centralizadas de política social y la creación de un mercado de programas sociales, donde múltiples iniciativas descentralizadas compiten por recursos y «clientes beneficiarios», objetivo estratégico de los programas de reforma institucional de corte neoliberal - como advierte Coraggio, Zicardi y Bodemer (1999:51)—, promovidos durante el régimen autoritario del presidente Fujimori, no parece haberse superado durante la gestión democrática del presidente Alejandro Toledo, sino más bien consolidado.

Los esfuerzos del CONAJU en términos de producción de información fueron valiosos, especialmente, porque proporcionaron elementos para la toma de decisiones con mayor perspectiva estratégica; sin embargo, lo paradójico es que las decisiones, las inversiones, la normatividad, los procedimientos, intervenciones, o de manera general las políticas en materia de juventudes dentro del Estado, no cambiaron sustantivamente a pesar de la información que comenzó a producirse y la institucionalidad creada.

El problema enfocado de manera más global —siguiendo las reflexiones de Mirko Lauer (2006) — consistió en que Alejandro Toledo usó políticamente su imagen entre los más pobres —nosotros agregaríamos también entre las juventudes - a fin de someterlos a la lógica de las políticas de liberalización de mercados, en este sentido le dio continuidad a las reformas económicas iniciadas por Fujimori, y tal vez por esta razón los resentimientos que generó fueron tan intensos. 
«Por eso en la historia de Toledo — opina Lauer- hay un elemento de traición étnica y política que no será fácilmente olvidado: nadie jugó con las esperanzas andinas como si se tratara de una esperanza personal. Ese fue uno de los motivos de que fuera tan intensamente detestado por una amplia mayoría durante la mayor parte de su gobierno».

Toledo sometió en general el proceso de transición democrática a la lógica de las políticas de liberalización de mercados. No existe otra razón para entender - como revelan las cifras presentadas por Julio Gamero (2006) — porque el PBI aumentó 25\% del 2001 al 2006; pero la pobreza, aún midiéndola con las cifras oficiales, sólo bajó de 6\% a 4\%. Las políticas sociales, y las políticas dirigidas a las juventudes, mantuvieron su condición de campos desarticulados de la política económica. La propuesta de «inclusión participativa» de las juventudes, sin definición clara ni precisiones, fue parte de esta desarticulación.

Las brechas que afectaron a las juventudes durante este periodo fueron más que evidentes. Las normas de liberalización del mercado laboral impuestas durante el régimen del presidente Fujimori, no sufrieron modificación alguna durante la administración del presidente Toledo, y continuaron afectando el ejercicio de los derechos de los trabajadores en general y de los jóvenes en particular. La «formación laboral juvenil», incluida en el Decreto Legislativo Nº728 Ley de Formación y Promoción Laboral, una de las principales normas de liberalización y flexibilización del mercado laboral en el Perú, en lo fundamental sometió a las juventudes a jornadas de trabajo con una subvención mensual por debajo del salario promedio, pagado a un trabajador adulto, a cambio de que el empresario recibiera al joven en su empresa.

Además las empresas prestadoras de servicios de intermediación laboral, las llamadas services, sumaron sus intereses a la problemática del empleo juvenil. La liberación del mercado laboral y su flexibilización permitió a los empresarios tercerizar parte de sus actividades productivas, a fin de ahorrarse el pago de derechos sociales a los trabajadores. Los principales afectados han sido y siguen siendo trabajadores jóvenes agobiados por el desempleo y el subempleo, que se han visto obligados a someterse a condiciones laborales en que -en la mayoría de los casos - tienen que renunciar a derechos sociales fundamentales. Incluso las condiciones laborales son tan extremadamente precarias que deben renunciar a condiciones mínimas de seguridad laboral, que ponen en riesgo la propia vida de los trabajadores: realización de trabajos de alto riesgo, sometimiento a jornadas labores por encima del régimen de las ocho horas, desconocimiento del descanso, la seguridad social, etc. 
Sin embargo, la precarización de la inserción laboral de las juventudes ha venido acompañada del surgimiento de un complejo y masivo fenómeno de violencia urbana protagonizada por jóvenes. La violencia juvenil no es un fenómeno que surge o se evidencia durante la gestión del presidente Toledo. La literatura especializada en ciencias sociales dedicada a estudios de juventudes en Perú, ha venido abordando este asunto desde por lo menos inicios de los noventa (Montoya, 2003). La particularidad es que este fenómeno se ha agudizado durante el periodo post transición democrática hasta convertirse en uno de los principales problemas de la sociedad peruana. La encuesta de Ipsos Apoyo, de abril del 2007, señala que el 45\% de los habitantes de la ciudad de Lima consideran que el principal tipo de violencia que existe a la fecha lo propician las pandillas y barras bravas (Salazar y García, 2008).

Las «barras bravas», las «manchas», las "pandillas», ${ }^{5}$ son expresiones del fenómeno de violencia juvenil en el Perú, registrado de manera similar en otros países de América Latina — como Kliksberg (2008) resalta-, ${ }^{6}$ y que no es difícil relacionar con las brechas que afectan al conjunto de la sociedad y en especial a las juventudes peruanas. Las principales ciudades del Perú reúnen hoy estas expresiones juveniles que muestran no sólo un fenómeno sociológico complejo, sino además antropológico, donde varias subculturas juveniles convergen. La característica que posee este fenómeno es que la violencia adquiere un protagonismo decisivo en su configuración.

\section{INCORPORACIÓN SEGMENTARIA DE LAS JUVENTUDES}

5 Las «barras bravas» son agrupaciones de jóvenes que simpatizan con algún club deportivo de fútbol y que generalmente terminan protagonizando enfrentamientos violentos con otras barras; las «manchas» son agrupaciones de jóvenes que giran en torno a relaciones de pares o amistad no necesariamente consolidadas y que son expresadas en espacios de socialización como fiestas o conciertos de música; las «pandillas» son agrupaciones de jóvenes unidos por lazos emocionales fuertes que establecen niveles de organización y jerarquía interna, buscan afirmar una identidad ligada generalmente a territorios definidos así como consolidar el dominio sobre el mismo, muchas veces protagonizan delitos menores.

6 Kliksberg (2008) sustenta la tesis de que la desigualdad, variable determinante de la pobreza, junto a la inseguridad y la violencia, han aumentado en América Latina en los últimos veinticinco años de manera epidémica, en paralelo al crecimiento económico. 
El presidente Alan García, representante del histórico Partido Aprista Peruano, partido político definido como de centro izquierda, fue uno de los candidatos que, en las elecciones presidenciales del 2006 en Perú, dirigió un discurso especialmente pensado para las juventudes. No era raro en él porque cinco años antes, en la campaña del 2001 que le resultó adversa, apeló también a recursos musicales y dancísticos juveniles. Su campaña incorporó expresiones del movimiento hip hop, un tema compuesto en género rap fue uno de los pilares de sus actos proselitistas, al igual que la inclusión de MC (Master of Ceremony o Maestro de Ceremonias propios del hip hop), además del breack dance, en mitines y actos proselitistas.

Las propuestas que esgrimió eran mensajes directos centrados en intereses juveniles: la eliminación de la intermediación laboral realizada por las services, empresas de servicios y colocación laboral, señaladas como las principales extorsionadoras de los jóvenes trabajadores; la ampliación y mejora del acceso a la educación y la tecnología; apoyo a la participación juvenil en la vida política y la administración pública.

García gana las elecciones del 2006, en segunda vuelta, imponiéndose primero a Unidad Nacional, alianza de partidos de derecha, liderada por Lourdes Flores; y después a Ollanta Humala, un militar retirado, con un acentuado discurso nacionalista, que canaliza la protesta de diversos sectores sociales contra el modelo económico neoliberal, heredado de Fujimori y que Toledo no modificó.

García con extrema habilidad orientó su propuesta, en un primer momento, a la crítica al modelo económico neoliberal, arrinconando a Lourdes Flores como representante de los «ricos»; y en un segundo momento, frente a Humala, propuso el «cambio responsable», convenciendo a las clases medias y altas de que no había mas remedio que votar por él, al menos sino querían que Humala y las masas populares levantadas ganaran las elecciones.

La gestión del presidente García fue iniciada con la puesta en la agenda pública de varios asuntos donde los protagonistas eran las juventudes. Su discurso de asunción de mando, pronunciado el 28 de julio de 2006, incluye dos iniciativas legislativas: la ley del concejal joven, que busca mejorar la participación política juvenil; y el incentivo a los mejores estudiantes de universidades públicas, a fin de que inicien sus carreras como funcionarios en la administración del Estado.

El presidente García logró que el Congreso de la República aprobara la primera. Él indica, para sustentar su iniciativa legislativa, que 
de las doce mil regidurías que hay en las municipalidades del Perú, sólo cinco por ciento están ocupadas por jóvenes. Por esta razón, plantea como mecanismo de discriminación positiva establecer una cuota del veinte por ciento en las listas de candidatos a regidores de municipalidades distritales y provinciales.

La propuesta fue aprobada por el Congreso el 10 de agosto de 2006 y promulgada al día siguiente como la Ley que promueve la participación de la juventud en las listas de regidores provinciales y municipales $\mathrm{N}^{\circ} 28.869$.

La norma — como lo indicó, la entonces presidenta del Congreso Mercedes Cabanillas - no establece la alternancia en la elaboración de las listas de candidatos, es decir, que se alternen adultos y jóvenes, a fin de evitar que los jóvenes sean ubicados en la cola de cada una de ellas. Lo que efectivamente ocurrió al poco tiempo durante las elecciones municipales y regionales de 2006, donde los diversos partidos, movimientos y organizaciones políticas, incluyeron jóvenes en sus listas; pero como añadidos o complementos para cumplir con la «cuota juvenil». Reportes posteriores a las elecciones municipales y regionales, realizadas en muchos casos por medios de comunicación masiva, confirmaron el restringido impacto de la norma y cómo diversas agrupaciones políticas manipularon la participación de las juventudes.

La otra iniciativa, que buscaba incentivar a los mejores estudiantes de universidades públicas para que iniciaran sus carreras como funcionarios del Estado, no logró ser aprobada en el Congreso.

Sin embargo, las iniciativas del presidente García adquieren un giro cuando el CONAJU desaparece por la fusión que experimenta con el Ministerio de Educación. El CONAJU desaparece por Decreto Supremo $\mathrm{N}^{\circ}$ 010-2007-ED, el 1 de marzo de 2007, como parte del proceso de reforma del Estado que implementa el propio presidente García.

No hubo mayores cuestionamientos a esta medida por lo mismo que el CONAJU había terminado convertido fundamentalmente en una instancia burocrática y especialmente poco eficaz para resolver y atender las demandas juveniles o proponer iniciativas en su favor. Algunas organizaciones e instituciones de la sociedad civil plantearon cuestionamientos a esta medida sin mayor fuerza o capacidad de presión para revertir la decisión puesta en marcha.

El CONAJU fue reemplazado por la Secretaría Nacional de la Juventud (SNJ), entidad adscrita al Ministerio de Educación y que asumía las tareas de formular y proponer políticas de Estado en materia de juventud, a fin de contribuir al desarrollo integral de los jóvenes en 
temas de empleabilidad, mejoramiento de la calidad de vida, inclusión social, participación y acceso a espacios en todos los ámbitos del desarrollo humano, así como promover y supervisar programas y proyectos en beneficio de los jóvenes.

El presidente García al igual que durante su campaña electoral ha usado, en diferentes momentos de lo que va de su mandato, imágenes atractivas que buscan seducir a las juventudes, medidas efectistas que causen impacto en la opinión pública y convenzan a la ciudadanía de que su gobierno tiene una sincera preocupación por las necesidades de las juventudes del Perú.

Una de esas medidas ha sido, por ejemplo, la presentación pública del Proyecto para la Promoción del Empleo Juvenil en América Latina (PREJAL), de la Organización Internacional del Trabajo (OIT), que inició sus actividades en Perú junto con los programas de empleo juvenil de las empresas Edelnor, Prosegur y Adecco, y que espera beneficiar a mil jóvenes en el país.

Iniciativa que suma su aporte a otra existente desde hace varios años, PROJOVEn, conducido por el Ministerio de Trabajo y Promoción del Empleo, con financiamiento del Banco Interamericano de Desarrollo, y que incluye una oferta de capacitación e inserción laboral.

El problema radica en que estas iniciativas no forman parte de una política sistemática en materia de juventudes, ni mucho menos de una política social consistente, sino que constituyen un conjunto de acciones que vienen implementándose de manera desarticulada y sin dirección. Otra vez vuelve a constatarse la misma situación de fragmentación de la política social y su separación radical de la política económica, similar a la registrada durante la gestión del presidente Toledo.

Las medidas implementadas durante la gestión del presidente García muestran claramente la búsqueda de una incorporación segmentaria de las juventudes, es decir, la asignación de recursos restringidos a sectores sociales, como las juventudes, que potencialmente pueden representar un cuestionamiento al orden social. Los resultados alcanzados en la reducción de la pobreza y el desempleo, por ejemplo, son más que evidentes para constatar esta incorporación segmentaria. Los resultados obtenidos no muestran cambios de fondo sino principalmente como sectores marginalizados y excluidos son beneficiados parcialmente de inversiones sociales de carácter compensatorio que no buscan transformar las relaciones de poder que sustentan su posición y condición de subordinación.

Las cifras oficiales señalan que la pobreza ha reducido su inci- 
dencia en el conjunto del país. La medición más reciente realizada por el Instituto Nacional de Estadística e Informática (2008), señala:

En el año 2007, el 39,3\% de la población del país se encontró en situación de pobreza, es decir, tenían un nivel de gasto insuficiente para adquirir una canasta básica de consumo, compuesto por alimentos y no alimentos. Esta proporción de pobres que tiene el país está conformado, por $13,7 \%$ de pobres extremos, es decir, personas que tienen un gasto per cápita inferior al costo de la canasta básica de alimentos y 25,6\% de pobres no extremos, es decir, personas que tienen un gasto per cápita superior al costo de la canasta de alimentos, pero inferior al valor de la canasta básica de consumo. La comparación de las cifras de la pobreza entre el 2006 y 2007, permite constatar una disminución de la tasa de pobreza en 5,2 puntos porcentuales, al haber pasado de una incidencia de $44,5 \%$ al $39,3 \%$. Durante estos años, la extrema pobreza se redujo en 2,4 puntos porcentuales, al pasar de $16,1 \%$ a $13,7 \%$ (2008:3).

Sin embargo, la incidencia de la pobreza no ha dejado de afectar a grupos sociales de atención prioritaria como las juventudes. El estudio antes citado anota: «Los jefes de hogares pobres y pobres extremos son, en promedio, más jóvenes que los jefes de hogar no pobres, según la información disponible. Esta característica se observa tanto a nivel nacional, urbano, rural y región natural» (2008:12).

La brecha por edad no ha sido cerrada ni mucho menos vulnerada a pesar de la importante reducción de la pobreza. La marginalización y la exclusión continúan teniendo rostros jóvenes.

La situación del desempleo es también similar. Un estudio de la Organización Internacional del Trabajo (OIT) señala que la tasa de desempleo juvenil urbano en Perú se situó en $14,8 \%$ en los tres primeros trimestres de 2007, nivel inferior al promedio de la región de América Latina de 21,4\%. Asimismo, el porcentaje alcanzado por Perú en los primeros nueve meses de 2007 es inferior al 15,1 por ciento registrado en similar período de 2006. Las estadísticas también indican que la tendencia del desempleo juvenil urbano en Perú es descendente desde el 2005, cuando registró un 16,1 por ciento para luego bajar a 14,9 por ciento en el 2006. Sin embargo, la OIT señala que a pesar de la caída de la tasa de desempleo a nivel de la región latinoamericana, entre ellos la del Perú, los jóvenes siguen siendo los más afectados por el desempleo. En ese sentido, la tasa de desempleo juvenil urbano en Perú fue 2.1 veces más que la de los adultos durante el 2007 (2007:21).

Los recursos asignados persiguen una satisfacción parcial de demandas permanentemente postergadas. No buscan resolver problemá- 
ticas de fondo sino simplemente cubrir potenciales cuestionamientos y sobre todo manipular sectores sociales que pueden abiertamente convertirse en radicales cuestionadotes del orden social, las políticas económicas y sociales que lo sustentan, así como del propio ordenamiento regido desde el Estado.

No es conveniente asumir que toda protesta o movilización puede adquirir un carácter crítico y de cuestionamiento al régimen político. La desideologización de las sociedades y la pérdida de peso de las organizaciones políticas y de la política en general en las sociedades contemporáneas, incluidas la peruana y las de América Latina, restan posibilidades de que los cuestionamientos protagonizados por movimientos sociales asumen una orientación política. No es difícil asumir, en este sentido, que la mayor parte de las juventudes son o están despolitizadas.

Sin embargo, es evidente que existe una politización objetiva de las protestas sociales en contextos de abierto cuestionamiento de los regímenes políticos y las políticas económicas y sociales de corte neoliberal, aplicadas en los últimos años en el Perú y América Latina.

Entonces, más allá de que las juventudes del Perú asuman un discurso ideológico o político en su sentido más general, como preocupación por lo público, su movilización y protesta puede rápidamente adquirir una connotación política al convertirse en crítica de las políticas implementadas desde el Estado.

A pesar de ello, quisiéramos insistir en que no es conveniente asumir que toda protesta o movilización puede adquirir un carácter crítico y de cuestionamiento al régimen político.

El surgimiento de diversas expresiones violentas, sobre todo en las ciudades del Perú, durante los últimos años: Las «barras bravas», las «manchas», las «pandillas», son formas de movilización social protagonizadas por jóvenes que no adquieren una connotación política; pero que sí expresan cuestionamientos, descontentos, malestares, frustraciones.

Las cuales muchas veces no logran ser canalizadas y explotan literalmente en las manos de la sociedad. Abordajes más recientes dedicados a la violencia juvenil comienzan a mostrar que estas diversas formas de expresión adquieren connotaciones cada vez más violentas. El uso de armas y el correspondiente tráfico de las mismas es creciente entre diversas «pandillas» (Prado, 2008).

Estas expresiones asumen connotaciones sociales, culturales y psicológicas, porque buscan cubrir los vacíos dejados por procesos de 
socialidad en general, o socialización en específico, inconclusos; construcción de identidades individuales y colectivas sustentados en lazos emocionales fuertes; producción de valores y sentidos de vida que cubran soledades e incertidumbres extremas; o simplemente de creación de un nosotros frágil y precario, pero reconocido por los y las jóvenes como necesario e inseparable de sus vidas.

\section{4. ¿POLITIZAR LAS POLÍticAs DE JUVENTUDES?}

Imaginar de una manera alternativa las políticas orientadas a las juventudes en un contexto de transición democrática, como el vivido en el Perú, supone asumir que el debate sobre ellas recién comienza y es clave para la consolidación del propio proceso de construcción democrática.

No podemos, por ello, dejar de mencionar que se ha erigido sobre dos paradojas: la primera es que la implementación de las políticas de ajuste, estabilización económica y liberalización de mercados, desde fines de la década pasada, provocó efectos negativos profundos en el acceso a la educación, la salud, el empleo y el ejercicio de la ciudadanía, en la población en general; pero particularmente en las juventudes. La situación generó una gran preocupación por la atención de este sector y al mismo tiempo permitió su lenta incorporación en la agenda de discusión pública. Lo paradójico es que a pesar que la agudización de la pobreza incidiera fuertemente en las juventudes no se haya institucionalizado hasta hoy, en el Perú, una política pública integral orientada a ellas desde el Estado.

La segunda paradoja es que el interés en el debate ha ido en paralelo al abandono de la discusión sobre las relaciones que las juventudes establecen con la política y el poder. El debate ha obviado este asunto, sin tomar en cuenta que las políticas de juventud son parte de relaciones de poder en las cuales las juventudes se ven inmersas; o que las demandas juveniles, en diferentes momentos históricos, generaron relaciones tensas con el Estado. Paradójicamente el debate ha adquirido una connotación apolítica y supuestamente alejada de la discusión sobre las relaciones de poder.

Ambas paradojas, desde nuestra perspectiva, ponen de manifiesto la complejidad que envuelve las relaciones entre juventudes y Estado; pero además muestran la necesidad de mirar desde otra perspectiva los procesos de constitución de las relaciones de poder que se dan en realidades como las nuestras, Perú y América Latina. Justamente, por ello, asumimos que es necesario incorporar en la discusión sobre la 
construcción democrática, y la ciudadanía, las perspectivas que sectores sociales como las juventudes poseen.

La especificidad de sus perspectivas, incluidas necesidades y demandas, supone retos al modelo democrático representativo impuesto en el Perú, porque plantea desafíos difíciles de cubrir al existir limitaciones de fondo generadas por las políticas económicas y sociales de liberalización de mercados.

No sólo las juventudes son los únicos sectores que resultan afectados por los procesos de marginalización y exclusión que estas políticas provocan. Otros sectores afectados también en el ejercicio de sus derechos tienen que ser tomados en cuenta e incluidos en el debate: mujeres, pueblos originarios, etc.

La incorporación de las perspectivas de las juventudes, en este sentido, forma parte de la discusión sobre qué democracia queremos construir y qué oportunidades generamos para que diversos sectores sociales puedan aportar a este proceso de construcción democrático.

Las políticas orientadas a las juventudes pasan tal vez, como plantea el Banco Mundial, por instrumentalizar la inversión en las juventudes como estrategia de lucha contra la pobreza en cinco transiciones: en el aprendizaje posterior a la edad de la educación primaria, al comienzo de una vida de trabajo productiva, en la adopción de un estilo de vida saludable, al momento de formar una familia y en el ejercicio de los derechos cívicos, así como usar lentes juveniles para centrar la atención de las políticas en las oportunidades, capacidades y segundas oportunidades (2006:5-11).

Sin embargo, y más allá de instrumentalizar la inversión en nombre de las juventudes y la lucha contra la pobreza, debe considerarse delegar poder a las juventudes a través de mecanismos democrático participativos que aseguren su representatividad, así como un ejercicio efectivo de su ciudadanía de manera integral. No como convidados de piedra sin capacidad de decidir sobre su destino y los asuntos públicos. Mecanismos que pueden aportar a mayores niveles de democratización de la gestión pública sin que ello implique sacrificar eficiencia y eficacia. Asunto que pasa por reconocer su participación política, a través de cuotas que aseguren de manera efectiva su inserción en el sistema político, no sólo a escala local sino también regional y nacional; pero también de instancias de control ciudadano donde las juventudes encuentren espacios públicos de deliberación e incidencia efectiva sobre las decisiones del Estado.

No es difícil deducir que el problema de las políticas de juventu- 
des en el Perú no sólo es de carácter técnico, administrativo o de gestión, sino también y fundamentalmente político, porque tiene que ver directamente con quién toma las decisiones, controla y define las orientaciones que se dan a los recursos públicos destinados a determinadas acciones.

Las políticas dependen de las particulares relaciones de poder que se dan en un determinado momento histórico dentro del Estado, de la voluntad de los actores involucrados, de las correlaciones de fuerza, de la institucionalidad establecida. No desconocemos la existencia de márgenes de acción que condicionan la acción política, sino que además de este elemento, que en sí mismo forma parte de las relaciones de poder, están las relaciones que los propios actores del juego político establecen.

Lo que pretendemos resaltar es - como señalan Repetto, Filgueira y Papadopulos (2006) — que esos márgenes de acción, para mutar en espacios de transformación, requieren estar apuntalados con recursos de poder, estructuras institucionales que abran oportunidades y, sobre todo, mucha capacidad de articular horizontes deseables con sentido práctico y oportunidad estratégica (2006:3).

$\mathrm{La}$ experiencia peruana es ilustrativa respecto a la carencia de recursos de poder necesarios para consolidar políticas orientadas a las juventudes. No sería justo no reconocer los esfuerzos, así como la honesta apuesta, que desenvuelven funcionarios y funcionarias encargados de políticas dirigidas a jóvenes, a fin de dotarlas de institucionalidad, a través del diseño de instrumentos de gestión, normatividad que las regule, producción de información y acciones de promoción en beneficio de diversas poblaciones juveniles. Sin embargo, el peso de lo «político» es superior y determina el destino final de lo «técnico».

Existe la necesidad de consolidar propuestas de políticas orientadas a las juventudes que afirmen su condición juvenil, a fin de poder contribuir a una efectiva democratización de las relaciones que establecen a nivel social con otros sectores como los adultos, con la perspectiva de consolidar sus capacidades y ampliar sus oportunidades, a la vez que sus posibilidades de diálogo intergeneracional; pero al mismo tiempo su posición en relación a las instituciones que controlan recursos y decisiones públicas.

No es suficiente, por lo tanto, con diseñar políticas sectoriales pensadas para jóvenes en aspectos como la generación de empleo, educación técnica y acceso a tecnológica, salud sexual y reproductiva, deporte y recreación, prevención de la violencia. Ni tampoco asumir 
sólo que el enfoque de juventudes debe ser transversal a las políticas públicas sectoriales.

El reto parece ser mayor y en alguna medida está amarrado a la necesidad de afirmar la condición juvenil. Tal vez el asunto central a debatir - como lo plantean Agiriano, Verruga y Castaño (2002) que retoman las tesis de Charvet, Andrieu y Labadie (2001) - es si la sociedad peruana, y las sociedades latinoamericanas, como en el caso de las sociedad europeas, vienen experimentado cambios de tal grado de profundidad que se está configurando un modelo de sociedad que paulatinamente asume la incertidumbre y el riesgo como parte de las relaciones entre sus ciudadanos (desregulación del mercado de trabajo, precariedad laboral, descenso de las retribuciones salariales, incertidumbre ante el futuro laboral y personal), ligada a un auge del neoliberalismo, una expansión de la economía globalizada, y a la extensión de las nuevas tecnologías de comunicación a todos los órdenes de la vida social y económica (2002:6).

El presupuesto es que estas transformaciones sociales y económicas vienen afectando notablemente la vida de la mayoría de los y las jóvenes, tanto de clases populares como medias y altas, y además en mayor medida que a las generaciones adultas, y de forma diferenciada con respecto a éstas. La incertidumbre de la época actual está provocando en los y las jóvenes consecuencias negativas, tanto en la relación con el trabajo y el acceso a la vida adulta, como en el plano de las relaciones personales, tal vez ahí radique una de las razones de fondo de la violencia protagonizadas por jóvenes.

No pretendemos homogeneizar a las juventudes y mucho menos desconocer su heterogeneidad, propia sobre todo de sociedades como las de Perú y América Latina caracterizadas por su heterogeneidad estructural, a nivel social, económico, cultural.

El hecho central a debatir, desde nuestro punto de vista, es si ahora las juventudes producto de los cambios de época, alargan su condición y generan códigos culturales propios y diferenciadores, consolidan estilos de consumo, gustos y modas que los identifican.

No es posible omitir además que los cambios que vienen experimentándose como resultado del proceso de transición demográfica, entendiendo por este el «proceso durante el cual se pasa de una dinámica de bajo crecimiento de la población, con altos niveles de mortalidad y fecundidad, a otra también de bajo crecimiento, pero con mortalidad y fecundidad reducidas; en el estadio intermedio se observan elevadas tasas de aumento de la población como resultado del desfase 
entre los inicios del descenso de la mortalidad y de la fecundidad». (CEPAL, 2008:3).

La transición demográfica contribuye al progresivo mayor peso que adquieren las personas en edades potencialmente productivas, sobre todo los jóvenes y los jóvenes adultos, en relación a las personas en edades potencialmente inactivas.

En este período, durante el cual la relación de dependencia desciende a valores nunca antes observados, se genera una situación particularmente favorable para el desarrollo, ya que aumentan las posibilidades de ahorro y de inversión en el crecimiento económico, en tanto que, al mismo tiempo, disminuye la presión sobre el presupuesto en educación. Para describir este período se han creado diversos términos, como por ejemplo «bono demográfico» o "ventana demográfica de oportunidades», que hacen referencia a las posibilidades que dicho período ofrece para elevar las tasas de crecimiento económico per cápita y los niveles de bienestar de la población (CEPAL, 2008:37).

Sin embargo, aunque el bono demográfico abre oportunidades, para que se traduzca en ventajas reales es preciso realizar considerables inversiones en capital humano, sobre todo en los jóvenes; además se requiere dar respuesta, en particular, a la oferta laboral de una población activa creciente y, simultáneamente, disminuir la inseguridad, la precariedad y la informalidad típicas del mercado laboral. Además conlleva nuevos desafíos para la sociedad, como adaptarse a una situación sin precedentes e implementar políticas que faciliten los ajustes necesarios en diversas áreas del quehacer público. La necesidad de tales ajustes implica cuestiones de equidad intergeneracional, en la medida en que se deben satisfacer las necesidades de personas en diferentes etapas del ciclo vital, y define el papel que cabe desempeñar en este proceso al Estado, los gobiernos regionales, las municipalidades, el sector privado, la sociedad civil, la comunidad, la familia. De ahí la importancia de aprovechar el bono demográfico, incluso como una forma de crear las condiciones para hacer frente al desafío que plantea el aumento de las personas mayores en la población (2008:37-38).

El aspecto central de nuestra argumentación no radica en resaltar el «bono demográfico» sino más bien que este supuesto «bono demográfico» genera mayores obligaciones en términos de inversión pública y por lo tanto exige políticas de mayor especialización y por lo tanto lecturas de la realidad de mayor complejidad.

Si efectivamente se alarga la condición juvenil hoy, es porque 
existen limitaciones estructurales de carácter social y económico que limitan que los jóvenes se independicen de las familias; si hoy cuesta más que antes ser adulto o iniciar una vida adulta, o existen menores posibilidades para desenvolverse como adulto, acceder a una educación de calidad, mantenerse en el empleo, iniciar una vida familiar propia, poseer seguridad social, jubilarse, etc. Existe la necesidad de diseñar políticas que respondan a este nuevo escenario y que, en lo fundamental tienen que poner en el centro de su atención a la condición juvenil.

Lo que incluye políticas que tomen en cuenta las culturas juveniles, el ocio y uso de tiempo libre propio de los y las jóvenes, además de aspectos sectoriales como la educación, la salud, el empleo; y no como aspectos instrumentales o estrategias para aproximarse a las juventudes o trabajar los temas sectoriales, sino para afirmar las propias culturas y expresiones juveniles.

La participación política aparece también como otro campo central de acción de las políticas orientadas a las juventudes, porque es justamente a través de su participación en las decisiones públicas y su ejercicio ciudadano pleno, que el conjunto de esta problemática podrá ser reconocida integralmente e incorporada a las decisiones públicas que se toman desde el Estado.

Evidentemente este conjunto de tareas forman parte de un programa complejo de acciones aún por debatir e implementar. La tarea aparentemente que se abre a futuro es politizar las políticas de juventudes para ampliar el canon democrático, apelando a las palabras de Boaventura de Sousa Santos y Leonardo Avritzer (2004).

LIMA (PERÚ), DICIEMBRE DE 2008

RECIBIDO: ENERO 2009

ACEPTADO: MARZO 2009

\section{REFERENCIAS BIBLIOGRÁFICAS}

Agiriano, Patxi; Edorta Verruga y José Andrés Castaño (2002): «¿Políticas integrales, afirmativas... o simplemente simulacros?». Estudios de Juventud $\mathrm{N}^{\circ} 59$. Madrid: INJUVE.

BANCO Mundial (2006): Informe sobre el desarrollo mundial 2007. El desarrollo y la próxima generación. Washington: Banco Mundial. 
CEPAL (2008): «Transformaciones demográficas y su influencia en el desarrollo en América Latina y el Caribe». Documento del trigésimo segundo periodo de sesiones de la CEPAL, Santo Domingo, República Dominicana, 9 al 13 de junio.

CoAguila, Jorge (2006): «Marginales, violentos y malditos/Al final de la calle». Disponible en: http://jcoaguila.blogspot.com.

COMISIÓN NACIONAL DE LA JuVENTUD (2004): Juventud y Estado. Oferta de servicios públicos 2004. Lima: CONAJU y GTZ.

Coraggio, José Luis; Alicia ZiCARdi y KlAus Bodemer (1999): «Las políticas sociales urbanas a inicios del nuevo siglo». Documento base de la Red de Políticas Sociales del Programa Urbal. Montevideo: Intendencia Municipal de Montevideo.

Charvet, D; P-J Andrieu y F. LABADIE (2001): Jeunesse, le devoir d'avenir. Paris: La Documentation française.

GAMERO, Julio (2006):. «Política económica y políticas sociales: entre el objetivo empleo y el 'grado de inversión'». La República, 13 de agosto, Lima.

GARCÍA, CARLOS (2006): «Agendas narrativas: una lectura de la narrativa peruana última». Espéculo. Revista de Estudios Literarios No33. Madrid: Universidad Complutense de Madrid.

INEI (2008): «Informe técnico: la pobreza en el Perú en el año 2007». Lima: INEI. KLIKSBERG, BERNARDO (2008): «¿Cómo enfrentar la inseguridad en América Latina? La falacia de la mano dura». Nueva Sociedad N²15. Caracas: Stiftung Friedrich Ebert.

— (1999): «Seis tesis no convencionales sobre participación». Buenos Aires: Centro de Documentación en Políticas Sociales, Gobierno de la Ciudad de Buenos Aires.

LAUER, Mirko (2006): «El virrey Toledo». La República, 26 de julio, Lima.

MONTOYA, LUIS (2006): «Políticas de juventudes, ‘inclusión participativa’ y jóvenes en el Perú». Última Década N²5. Valparaíso: Ediciones CIDPA.

— (2003): «Poder, jóvenes y ciencias sociales en el Perú». Última Década No18. Viña del Mar: Ediciones CIDPA.

Organización Internacional Del Trabajo (2007): Panorama laboral 2007 América Latina y el Caribe. Lima: OIT, Oficina Regional para América Latina y el Caribe.

Planas, Enrique (2007): «Los hijos de la violencia». El Comercio, 29 de septiembre, Lima.

PRADO, GABRIEL (2008): «Perú podría tomar un camino parecido al de las maras centroamericanas si no implementa política de seguridad eficaz». Disponible en: http://ideeleradio.blogspot.com.

QuiJAnO, ANíBAL (1991): «Poder y crisis en América Latina». Lima: Centro de Estudios y Publicaciones.

Repetto, Fabián; Fernando Filgueira y Jorge Papadopulos (2006): «'La política’ de la política social latinoamericana. Análisis de algunos 
retos fundamentales y esbozo de sus escenarios sobresalientes». Documento del foro: la política de la política social. Washington: INDES/BID.

SAlAzAr VeGA, ElizABeth y Luis García PANTA (2008): «Policía detecta pandillas que compran armas de uso militar y trafican drogas». El Comercio, 24 de marzo, Lima.

SANTOS, BOAVENTURA DE SOUSA y LEONARDO AVRITZER (2004): «Introducción: para ampliar el canon democrático». BOAVENTURA DE SOUSA SANTOS (coordinador): Democratizar la democracia. Los caminos de la democracia participativa. México: FCE. 